\title{
Blood-stream infection and atrial thrombus due to a buried and forgotten permanent haemodialysis catheter
}

\author{
Yalcin Solak, ${ }^{1}$ Osman Koc, ${ }^{2}$ Abduzhappar Gaipov, ${ }^{1}$ Orhan Ozbek, ${ }^{2}$ Zeynep Biyik, ${ }^{1}$ Mehdi Yeksan ${ }^{1}$ \\ ${ }^{1}$ Nephrology Unit, Department of Internal Medicine, Meram School of Medicine, Konya University, Konya, Turkey \\ ${ }^{2}$ Department of Radiology, Meram School of Medicine, Konya University, Konya, Turkey
}

Correspondence to Dr Abduzhappar Gaipov, abduzhappar@gmail.com

\section{DESCRIPTION}

An 80-year-old man maintenance haemodialysis patient was admitted to the haemodialysis inpatient unit with complaints of chills and fever after haemodialysis sessions. The patient had been undergoing haemodialysis for 3.5 years thrice weekly. One year prior to current admission his right-sided permanent haemodialysis catheter was withdrawn and a new permanent catheter was inserted on the same side in another centre. Chest $\mathrm{x}$-ray (figure 1A) showed that there were two catheter images in the right chest. The catheter which was thought that previously was taken out was still in place. The catheter was broken in the subcutaneous tunnel but the catheter tip was still in the right ventricular cavity. The second catheter image belonged to the current functional catheter. It lay parallel to the previous catheter until the right atrial caval vein junction. Procalcitonin level was $92.93 \mathrm{ng} / \mathrm{ml}$. The patient was administered broadspectrum antibiotics after blood cultures were taken. Interventional radiology tried to extract the broken catheter with angiography. The catheter tip was tried to be removed from the right ventricle via macrosnare but catheter was stuck to the ventricle wall (figure 1B). Transthorasic and subsequently transoesophagial echocardiography did not reveal thrombus or vegetation. Thus, the patient underwent surgical catheter removal operation. During atriotomy, it was observed that the forgotten catheter extended into the right ventricular cavity and adhered to the ventricle wall. There were vegetations and organised thrombi in the posterior wall of the right

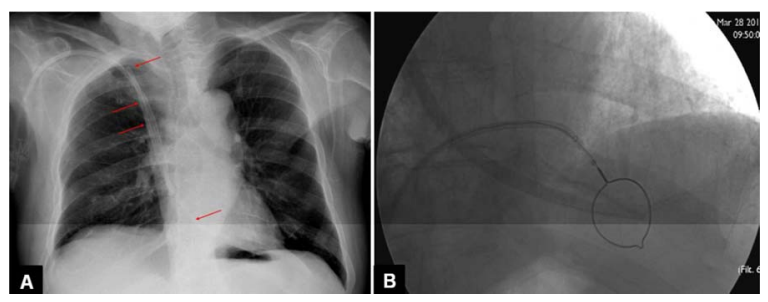

Figure 1 (A) Posterior-anterior chest $x$-ray showing two catheter images, one belongs to the current functional tunneled catheter. The other catheter image belongs to the broken and forgotten tunneled catheter (arrows). The tip of the broken catheter extends till the right ventricular cavity. (B) Interventions from right femoral vein and left internal jugular vein to take the broken catheter out with macrosnare. atrium. The broken catheter was taken out without any complication, the earlier catheter was also removed and a new permanent catheter was inserted to the left side (figure 2). All the blood cultures obtained during the peak of fever, and from the earlier catheter were negative. The patient had no chills and fever after haemodialysis sessions, and procalcitonin level decreased to $0.49 \mathrm{ng} / \mathrm{ml}$ at the end of the treatment.

Catheter care is of utmost importance to prevent infection and to prolong catheter life. ${ }^{1}$ Removal of inserted catheter should be performed in the cases of catheterrelated infection and thrombus, damaged catheter or its occlusion, and at the end of the treatment. Removal shall be undertaken under aseptic conditions by experienced personnel who know all the parts of the inserted permanent catheter. It may require local anaesthesia and a small surgical incision to remove the cuff of the catheter. Controlled pressure shall be applied by the clinician until haemostasis is achieved and minor sutures could be provided for incision if symptoms of bleeding are observed. ${ }^{2} 3$ Also some post removal checklist should be made to prevent complications: first, instruct the patient to call the physician on call for any symptoms of bleeding or infection, be sure that all components of catheter were completely removed, check the site after 10-15 min for

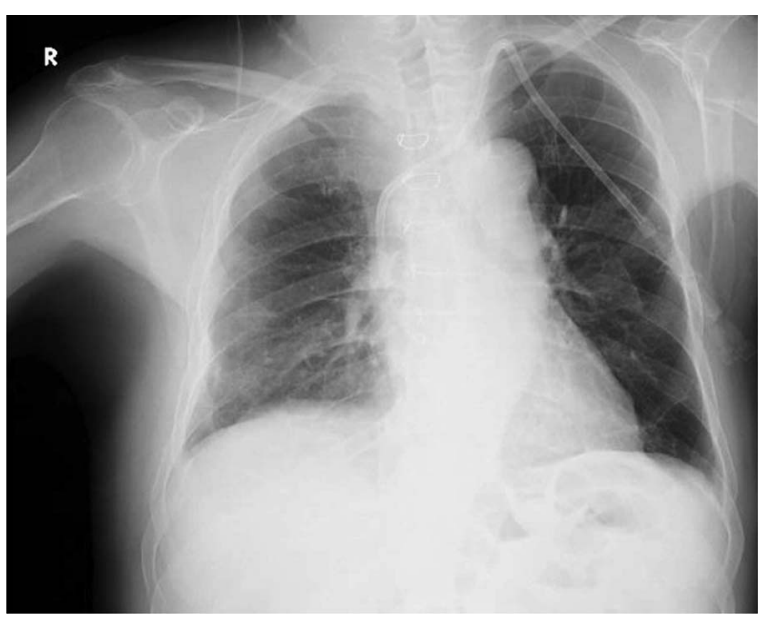

Figure 2 Postoperative control chest $x$-ray showing replaced permanent catheter to the left side (opposite side) and traces of postoperative sutures. 


\section{BMJ Case Reports}

subcutaneous bleeding and check up the cardiovascular and pulmonary systems for any possible internal bleeding and air embolism. Provide the control ultrasound or chest x-ray if necessary. ${ }^{4}$ This case illustrates a marginal example of a mismanaged permanent haemodialysis catheter that led to serious blood stream infection and required a major surgical operation for its removal.

\section{Learning points}

- Self-removal of the catheter by the patient or its uncontrolled removal by inexperienced personnel can lead to various complications, such as bleeding, infection, air embolism or thrombosis and even loss of part of the catheter.

- Removal of central venous catheter should be undertaken by experienced personnel in aseptic conditions according to established protocols and postoperative checklist to avoid various complications.

\section{Competing interests None.}

Patient consent Obtained.

\section{REFERENCES}

1. Lincoln M. Preventing catheter-associated bloodstream infections in hemodialysis centers: the facility perspective. Nephrol Nurs $J$ 2011;38:411-15; quiz 6

2. Cleary-A M. Insertion and management of haemodialysis catheters guideline. Australian Commission on Safety and Quality in Health Care, National Safety and Quality Health Service; Document Number QH-GDL-321-6-4:2012:1-17. http://www.health.qld.gov.au/qhpolicy/docs/gdl/ qh-gdl-321-6-4.pdf (accessed 13 Aug 2012).

3. Ash SR. Advances in tunneled central venous catheters for dialysis: design and performance. Semin Dial 2008;21:504-15.

4. South S, Peett A, Roberts C. Insertion and Management of Central Venous Catheters (CVCS). Gloucestershire Hospitals, NHS Foundation Trust. Issue Date: November 2007:1-103. http://www.gloshospitals.org.uk/SharePoint1/ Clinical\%20Polices/A0032.pdf (accessed 13 Aug 2012).

Copyright 2012 BMJ Publishing Group. All rights reserved. For permission to reuse any of this content visit http://group.bmj.com/group/rights-licensing/permissions.

BMJ Case Report Fellows may re-use this article for personal use and teaching without any further permission.

Please cite this article as follows (you will need to access the article online to obtain the date of publication).

Solak Y, Koc 0, Gaipov A, Ozbek 0, Biyik Z, Yeksan M. Blood-stream infection and atrial thrombus due to a buried and forgotten permanent haemodialysis catheter. BMJ Case Reports 2012;10.1136/bcr-2012-007365, Published XXX

Become a Fellow of BMJ Case Reports today and you can:

- Submit as many cases as you like

- Enjoy fast sympathetic peer review and rapid publication of accepted articles

- Access all the published articles

- Re-use any of the published material for personal use and teaching without further permission

For information on Institutional Fellowships contact consortiasales@bmjgroup.com

Visit casereports.bmj.com for more articles like this and to become a Fellow 